\title{
Laboratory tests of overpressure differential systems for smoke protection of lobbies
}

\author{
Paweł Szałański ${ }^{1, *}$, Jacek Misiński ${ }^{1}$ \\ ${ }^{1}$ Department of Air Conditioning, Heating, Gas Engineering and Air Protection, Faculty of \\ Environmental Engineering, Wrocław University of Science and Technology, 4/6 C.K. Norwida st. \\ 50-373 Wrocław, Poland
}

\begin{abstract}
Paper presents the methodology of laboratory tests for ventilation overpressure differential systems for smoke protection of lobbies. Research area consists of two spaces representing the lobby and the area under fire equipped with proper ventilation installation. This allows testing of overpressure differential systems for smoke protection of lobbies. Moreover, piece of laboratory tests results for two selected smoke protection systems for lobbies are presented. First one is standard system with constantly opened transfer-damper mounted between lobby and area under fire. Second one - system with so called "electronic transfer" based on two dampers (supplying air to a lobby and to unprotected area alternatively). Opening and closing both dampers is electronically controlled. Changes of pressure difference between lobby and fire affected area during closing and opening doors between those spaces is presented. Conclusions, concerning the possibility of meeting the time period criteria of pressure difference stabilization required by standards, are presented and discussed for both systems.
\end{abstract}

\section{Introduction}

Pressure differential systems (PDS) are the method implemented to maintain safe conditions (lack of smoke) in protected areas, especially in escape routes. The task of PDS is to provide proper pressure gradient to obtain proper flow direction of clean air (free of smoke). In pressurization system pressure should decrease: starting from maximum value in the protected space to lower values in next spaces. Full examination of the system requires not only laboratory tests, but also final adjustment and tests in existing building. Results of the laboratory tests should present that the PDS is able to maintain proper pressure gradient and air flows for full range of operating conditions and for particular air tightness range of protected area.

Operation of two types of PDS's are analyzed in the present paper. First one is standard system with constantly opened transfer-damper mounted between lobby and fire affected area (System 1). Second system with so called "electronic transfer" [1] based on two dampers (supplying air to a lobby and to unprotected area alternately) which opening

\footnotetext{
*Corresponding author: pawel.szalanski@pwr.edu.pl
} 
sequence is electronically controlled (System 2). In recent years such a systems appeared on Polish market [1].

\section{Laboratory test procedures}

Following papers [2], [3], [4], [5] are showing basic aspects of pressure differential systems laboratory testing procedures designed to keep smoke behind a leaky physical barrier in a building, such as doors or other openings. Meanwhile, in recent years the group of specialists (the Technical Committee CEN/TC 191/SC1) is working on changes in standard [6] to provide uniform test procedure for pressure differential systems. The considerations contained in above mentioned sources and information about the Technical Committee actual work results on EN12101-6 standard are referring mainly to the case of stairwell protection. However, in this paper the investigation guidelines of pressure differential systems for lobbies are described. It was decided that laboratory testing procedures should be similar to those described in above mentioned sources. In such a case the following tests should be performed:

- first functionality test, Fu - opening and closing the door cycle repeated 20 times in the time sequence: $\mathrm{t}_{1}=1 \mathrm{~s}-$ door opening time, $\mathrm{t}_{2}=6 \mathrm{~s}-$ door opened, $\mathrm{t}_{3}=3 \mathrm{~s}-$ closing time, $\mathrm{t}_{4}=6 \mathrm{~s}-$ door closed,

- durability test, Du -opening and closing the door cycle repeated 10,000 times in the time sequence: $t_{1}=1 \mathrm{~s}-$ door opening time, $\mathrm{t}_{2}=0 \mathrm{~s}-$ door opened, $\mathrm{t}_{3}=3 \mathrm{~s}$ - closing time, $\mathrm{t}_{4}=0 \mathrm{~s}-$ door closed,

- second functionality test, $\mathbf{F u}$ - opening and closing the door cycle repeated 20 times in the time sequence: $\mathrm{t}_{1}=1 \mathrm{~s}-$ door opening time, $\mathrm{t}_{2}=6 \mathrm{~s}-$ door opened, $\mathrm{t}_{3}=3 \mathrm{~s}-$ closing time, $\mathrm{t}_{4}=6 \mathrm{~s}-$ door closed,

- oscillating test, Osc - opening and closing the door cycle repeated 20 times for various values corresponding to door opening angles without waiting time $\left(\mathrm{t}_{2}=\right.$ $0 \mathrm{~s}$ and $\mathrm{t}_{4}=0 \mathrm{~s}$ ).

These tests should be performed in the order given above, using the same PDS kit and the same test rig. Replacement of system components is not allowed. According to above mentioned papers, criteria for evaluation of PDS test results are proposed:

1-during each cycle sequence of the functionality test and after last cycle of oscillating test the time period to reach the lower limit of the nominal flow rate $\mathrm{V}=0,9 \cdot \mathrm{V}_{\mathrm{n}}$ (flow rate through the door between test room 2 and 3 ) should be not longer than $\Delta \mathrm{t}_{\mathrm{v}}=3 \mathrm{~s}$ after the door is fully opened (Fig. 1),

2 - during each cycle sequence of the oscillating test and after last cycle of oscillating test the upper limit for the pressure criterion equals to $\Delta \mathrm{p}_{\max }=1,2 \cdot \Delta \mathrm{p}_{\mathrm{n}}$ should not be exceeded during the time not longer than $\Delta \mathrm{t}_{\mathrm{p}}=3 \mathrm{~s}$ Where: $\Delta \mathrm{p}_{\mathrm{n}}$ - nominal pressure differential to be maintained by the PDS kit with closed door between room 2 and 3 (Fig.1),

3 - in steady state, the measured pressure difference between the test rooms 2 and 3 , with the door closed, should not be less than $80 \%$ of the nominal pressure and not less than $35 \mathrm{~Pa}$ as the absolute limit for the system where $\Delta \mathrm{p}_{\mathrm{n}}=50 \mathrm{~Pa}$.

\section{Description of the laboratory}

Test rig schematics are shown in Fig. 2 and 3. Below described layout of room, ducts systems and measuring system is the part of laboratory built for testing different PDS's 


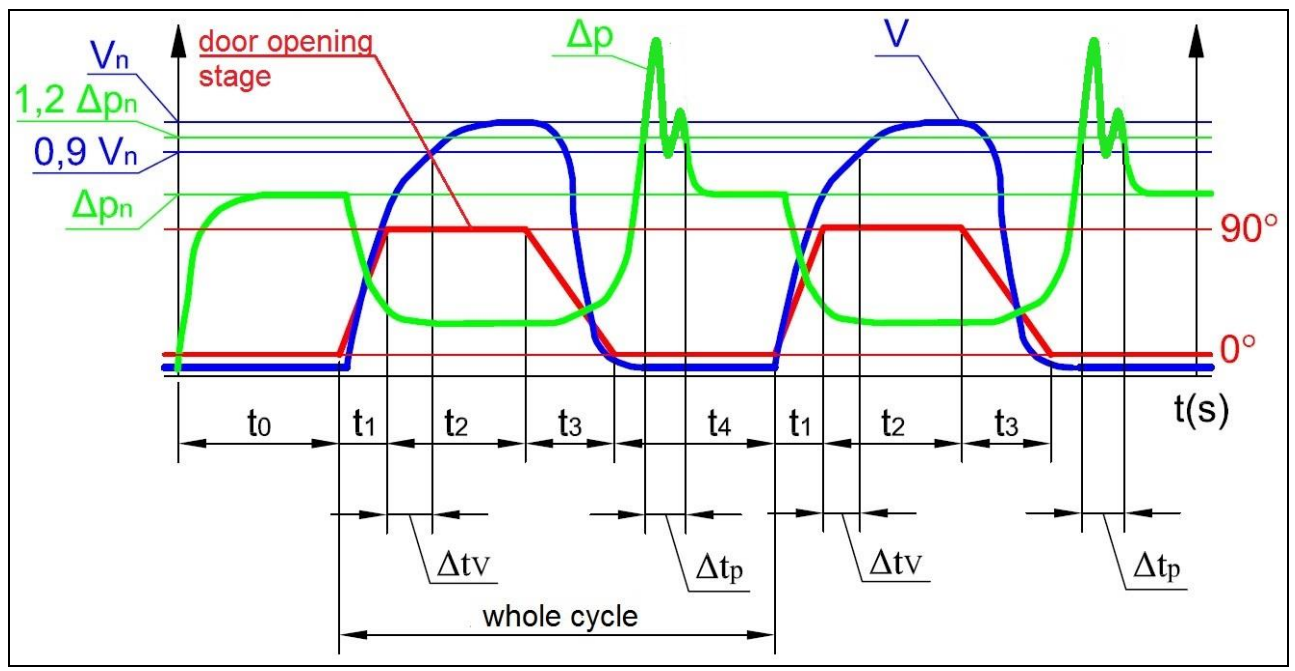

Fig. 1. Pressure and volume flow rate criteria based on $[2,3,6]$

intended for protection of escape routes. The case described in this paper concerns overpressurisation of lobby in escape route. Test room 2 corresponds to protected area with increased pressure - lobby. Test room 3 corresponds to fire affected area. The volume of each room is about $124 \mathrm{~m}^{3}$ and $138 \mathrm{~m}^{3}$ respectively. Height of the rooms is $3,8 \mathrm{~m}$.

System 1 has a duct supplying air only to the room 2 . The idea of the system 2 configuration is based on supplying air to both rooms ( 2 and 3 ) by the fan placed in room 4 through branched duct system (Fig.3). Each duct branch has its own motorised volume control damper and flow meter. The fan supplies outside air to both rooms alternately.

Supplied air flows from test room 2 (protected area) to the room 3 (fire affected area). In case of System 1 air flows from room 2 to 3 through door and through transfer damper (adjustable pre-set opening in the wall) - Fig.2. In case of System 2 air flows through the door - Fig. 3.

There are two methods of air release from room 3:

- natural air release through openings in external wall,

- mechanical air release - fan exhaust system.

The first case is described in this paper.

Supply fan inlet duct is equipped with conical inlet and four wall pressure tappings to measure the fan capacity. Before system investigation there was room 2 air tightness determined using testing tool P.A.N.D.A., Airflow. Leakage flow rate $\mathrm{V}_{1}$ for overpressure of $50 \mathrm{~Pa}$ was measured with this tool.

Different values were measured, especially:

- pressure drop along inlet cone,

- dynamic pressures on measuring crosses in VAV dampers (rooms 2 and 3),

- pressure difference:

o between rooms 2 i 3 ,

o test room 2 - reference pressure,

- opening angle of damper blades (opening angle of escape door).

Air flows through the ducts were calculated basing on measured pressure drop on inlet cone (for known characteristic) and pressure difference on measuring crosses. All measurements and calculations were based on pressure transducers readings. Measuring equipment of presented pressure difference (Fig.4 and 5) gives results with accuracy of $\pm 1 \mathrm{~Pa}$. 
There is PC station implemented for controlling the damper simulating door and collecting data in each test.

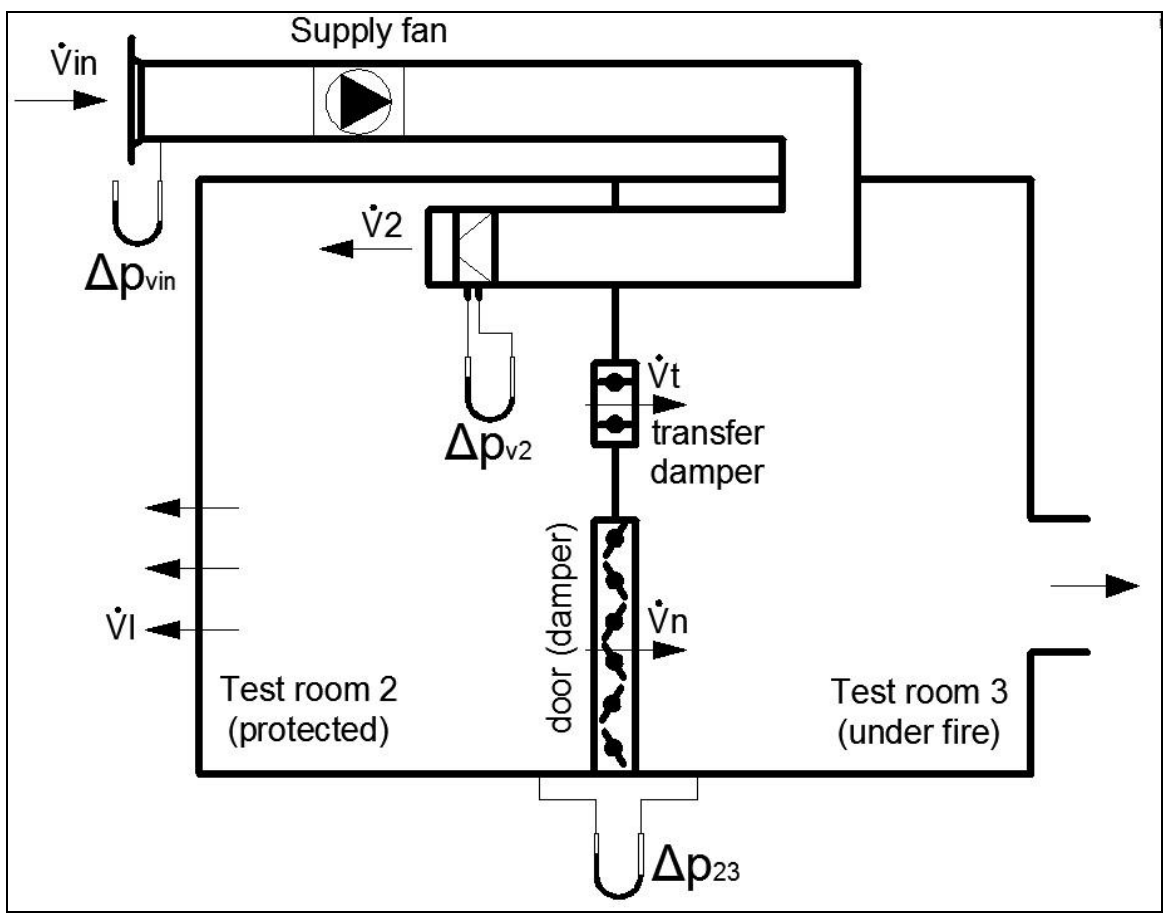

Fig. 2. Diagram of a test rig for standard system (system 1)

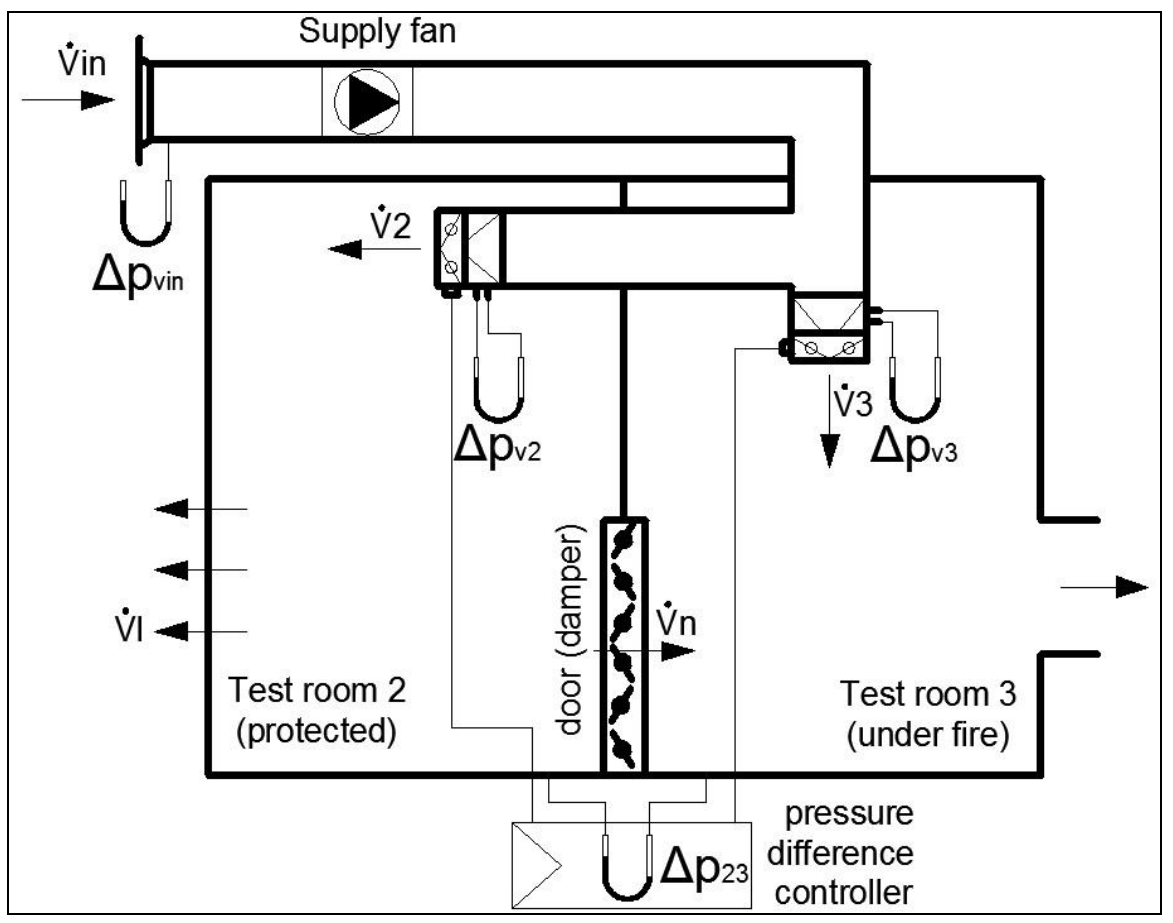

Fig. 3. Diagram of a test rig for system with "electronic transfer" (system 2) 


\section{Description of examined systems}

The following section presents selected results of the measurements carried out on the above described test rig. The results are presented for two tested PDS's for smoke protection of lobbies.

System 1 is a standard system with constantly opened transfer-damper mounted between lobby and area under fire. The system contains:

- air supply fan operating at constant speed,

- fixed (constantly opened) transfer vent.

The system does not require electronic controllers. With closed doors between the zones, the air flow should cause the pressure drop at the transfer vent equal to the required pressure difference between the zones. While, when the door is opened, the speed in the door opening should reach the required value $(\mathrm{Eq} 2 \mathrm{~m} / \mathrm{s})$.

System 2 with so called "electronic transfer" is based on two dampers supplying air to the lobby and to the area under fire alternately. Their position is electronically controlled. Adjustment of overpressure values in the protected area by changing damper's positions is performed by the SMVEST6 controller by Control System Company [7]. The system contains:

- air supply fan operating at constant speed,

- pressure transducer for measuring the pressure difference between the protected and fire affected zone,

- two motorized multileaf dampers on air supply ducts, one for the protected zone and the other for the fire affected zone,

- controller of pressure difference between zones.

Pressure difference controller is set to keep constant value of pressure difference between zones by proper positioning of the air dampers. Software dedicated to contol the system has self-learning function. It is suitable for controlling different types of dampers with different characteristics of fire protection areas. The supply air flow to both zones varies depending on the current state of the door opening between the zones. In the case where the air release path from the protected area is closed, the air damper to the zone is in the minimum opening position, providing overpressure and covering air leakage. In the same time, the second damper is in a position of considerable opening and directs most of the supplied air to unprotected area. When the door is opened, the pressure in the lobby rapidly decreases. This causes opening the damper supplying air to the lobby and closing the damper to the unprotected area. Consequently, the amount of air supplied to the protected zone increases to achieve the required air speed in the door between the lobby and the fire affected area. Investigated system was set to maintain average air velocity of $2 \mathrm{~m} / \mathrm{s}$ in $2 \mathrm{~m}^{2}$ cross-section of opened door. It means that the necessary air flow was equal at least $\mathrm{V}_{\mathrm{n}}=14400 \mathrm{~m} 2$. The other air flows $\mathrm{V}_{\mathrm{in}}, \mathrm{V}_{2}, \mathrm{~V}_{3}, \mathrm{~V}_{\mathrm{t}}$ and pressure differences $\Delta \mathrm{p}_{\mathrm{v} 2}, \Delta \mathrm{p}_{\mathrm{v} 3}, \Delta \mathrm{p}_{\mathrm{in}}$ were result of system operation. Above mentioned results were obtained with room air leakage up to $\mathrm{V}_{\mathrm{l}}=600 \mathrm{~m}^{3} / \mathrm{h}$ at $50 \mathrm{~Pa}$ overpressure in the room.

\section{Sample test results}

Below you will find selected test results for both systems. Measurements for System 2 are preliminary and have been carried out during the development works on the SMVEST6 by Control System Company [7]. Both systems have been set up to provide:

- flow velocity of at least $2 \mathrm{~m} / \mathrm{s}$ in the open doorway,

- overpressure $\Delta \mathrm{p}_{\mathrm{n}}=45 \mathrm{~Pa} \pm 20 \%$ in the protected area against the unprotected area. 
Figures 4 and 5 show the measured variations in the pressure difference between protected and unprotected zones. Presented diagrams show part of functionality test results. One can see that the investigated systems fulfil above mentioned requirements of criteria 1 in presented cycles of functionality test. Preliminary analysis of test results carried out by authors shown that in $3 \mathrm{~s}\left(\Delta \mathrm{t}_{\mathrm{v}}\right)$ after fully door opening system reaches at least $90 \%$ of capacity enough for obtaining $2 \mathrm{~m} / \mathrm{s}$ in the doorway and in this state of work system maintains required capacity $\mathrm{V}_{\mathrm{n}}$. However, results are preliminary and need confirmation.

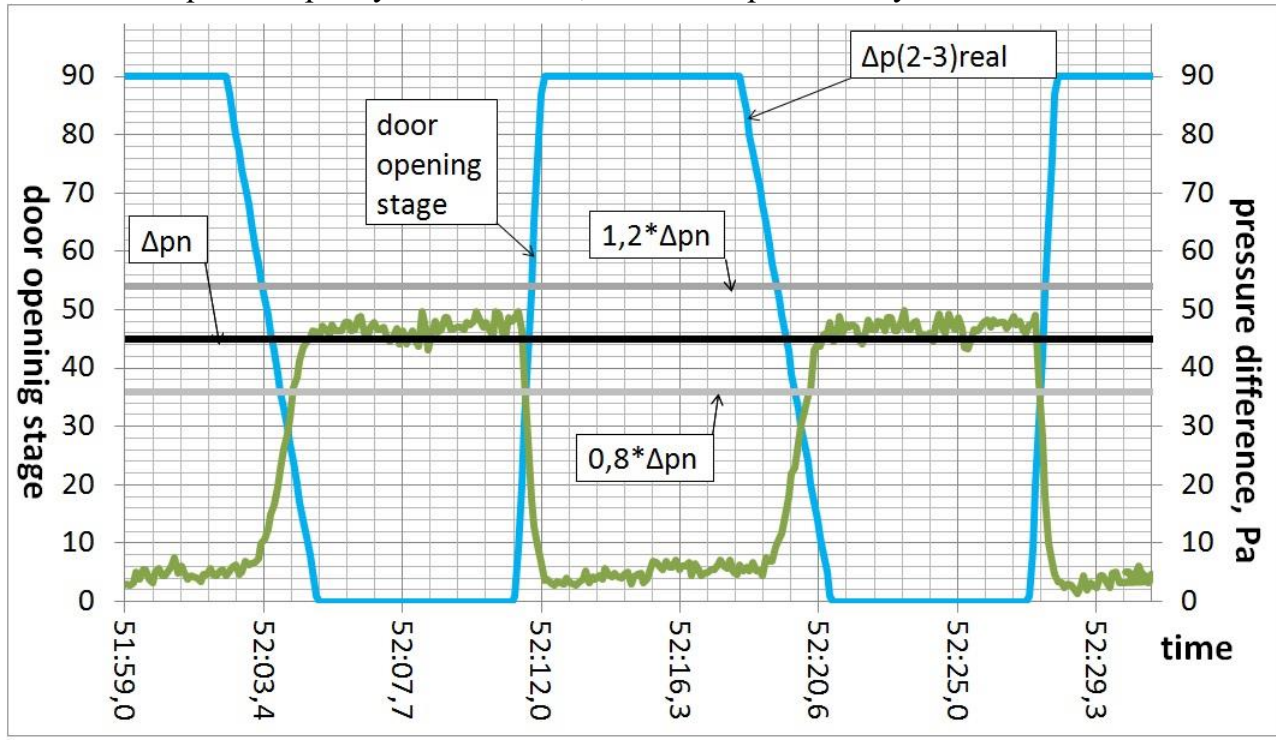

Fig. 4. System 1 - differential pressure - functionality test ( 2 selected cycles), abbreviations: $\Delta \mathrm{p}_{(2-3) \text { real }}$ - measured difference pressure between lobby and unprotected zone,

$\Delta \mathrm{t}_{\mathrm{p}}$ - pressure regulation time period

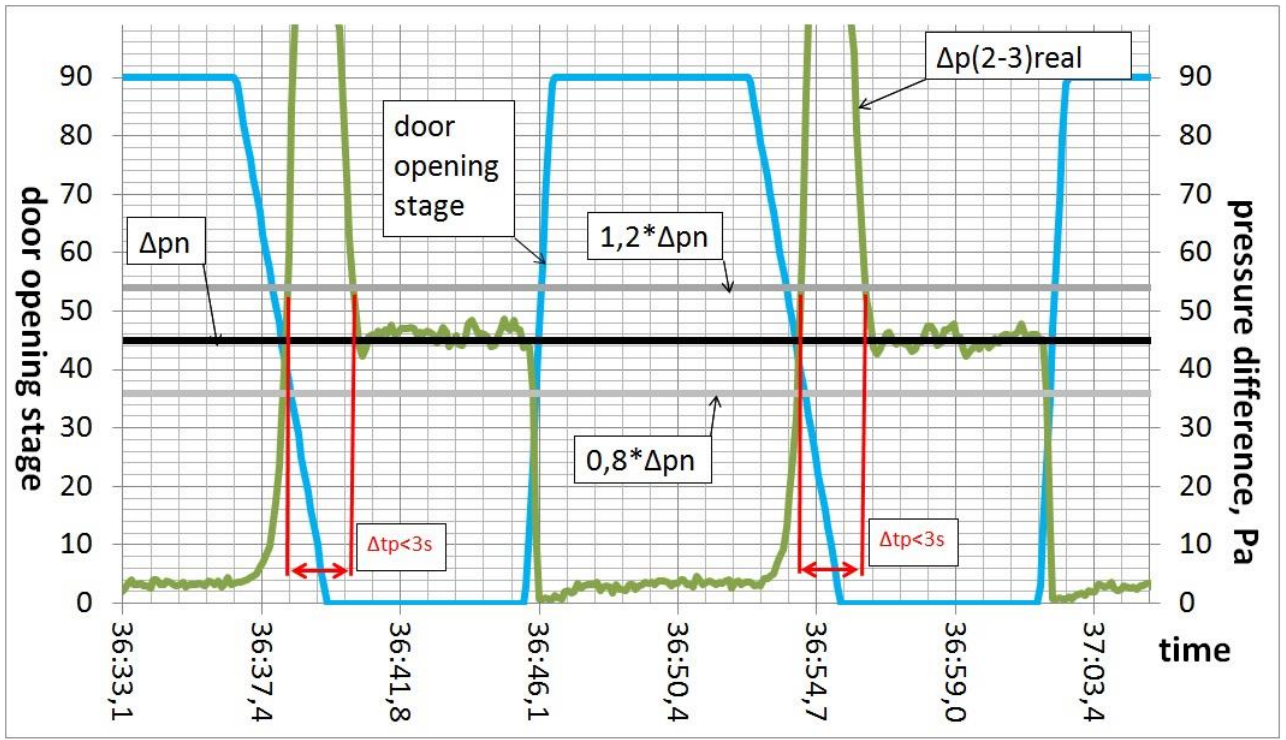

Fig. 5. System 2 - differential pressure - functionality test ( 2 selected cycles), abbreviations: $\Delta p_{(2-3) \text { real }}$ - measured difference pressure between lobby and unprotected zone, $\Delta \mathrm{t}_{\mathrm{p}}$ - pressure regulation time period 
After closing the door (closure time: $3 \mathrm{~s}$ ), each system responds in different way. For system 1 , when the door was closed, there is no increase of the value of pressure difference between the analyzed zones. On the other hand, in the system 2 the door closure causes a sudden increase of this pressure difference and few seconds period of exceeding the value of $\Delta \mathrm{p}_{\max }=1,2 \cdot \Delta \mathrm{p}_{\mathrm{n}}$. In the analyzed cycles it lasts no longer than $\Delta \mathrm{t}_{\mathrm{p}}=3 \mathrm{~s}$. Similar effects were observed during examination of System 2 with mechanical (fan) air release from unprotected area.

\section{Summary}

Based on the results of the tests, the comparison of two analyzed PDS's for smoke protected lobbies was presented. Major discrepancy between them is the variation of the pressure difference between the protected and unprotected zones while closing the door. Manufacturers of systems with electronically controlled transfer, e.g. [1], are pointing out advantages:

- limiting the dimensions of the air transfer units,

- proper controlling of the overpressure in protected escape routes,

- constant monitoring of the operation of equipment performance, thereby reducing the duration of the commissioning and performance tests on site.

The above mentioned features should be considered as advantages, especially because often the dimensions of lobbies do not allow for the installation of transfer vents. However, one should consider that the system without constantly open transfer-vent causes temporary increase of the pressure difference between the protected and unprotected zones. Too high pressure difference between these spaces is unfavorable. This may make escape from fire affected area impossible during few seconds. Therefore these systems must be built so that the time of exceeding the permissible pressure differences is no longer than required by the regulations. These should be subject of appropriate testing. The authors of such systems suggest that these are suitable for small lobbies. In such a case we are planning to repeat tests for different volumes of lobbies to confirm that lobby volume does not significantly influence on the range of pressure difference variations between zones. The research carried out at the laboratory does not only serve to study existing pressure differential systems, but also provides opportunities for their development. The presented principles of anti-smoke inspection systems do not cover all work scenarios and installation variants. The actual operation of the lobby during evacuation may differ significantly from the scenario set. Already at the design stage, the designer should have access to the information about building leakage range for which planned system has been tested. During PDS testing, the range of stable operation of the system should be specified, ie the maximum and minimum leakages of the protected zone. Test should be repeated for adjustable leakages of test room (protected zone).

\footnotetext{
Above described test rig is the part of laboratory built by Control System company in Błonie near Wrocław in cooperation with Wroclaw University of Technology and FlaktBovent Company. Authors would like to thank these Companies for sharing the laboratory to give us possibility to carry out research of different systems based on our own ideas and also to take part in research of a new products supplied by manufacturers.
} 


\section{References}

1. Website:http://smay-products.1000i.pl/wpcontent/uploads/2017/02/Smay_Roznicowanie_Cisnienia_Przewodnik_2013a v523-PL_pdf, 28.03.2017r.

2. J. Misiński, M. Sompoliński, P. Szałański, Air, Heat and Energy in Buildings (2014), p. $135-140$

3. J. Misiński, M. Sompoliński, P. Szałański, INSTAL, 356, 11 (2014), p. 42-44

4. P. Głąbski, SITP Seminar (The Association of Fire Engineers and Technicians Poland), „Fire protection - spring 2010”, 18-21 march 2010, Zakopane, s.1-5

5. P. Głąbski, Fire Protection published by SITP (The Association of Fire Engineers and Technicians Poland), 2 (2010), s.17-19

6. EN 12101-6:2007 Smoke and heat control systems - Part 6: Specifications for pressure differential systems - Kits

7. SMVEST6 Data Sheet, Control System 